Research Article

\title{
Fatigue Assessment of Monopile Supported Offshore Wind Turbine under Non-Gaussian Wind Field
}

\author{
Bing Li, ${ }^{1}$ Kang Rong, ${ }^{1}$ Haifeng Cheng, ${ }^{2}$ and Yongxin $\mathrm{Wu} \mathbb{D}^{3}$ \\ ${ }^{1}$ Key Laboratory of Concrete and Prestressed Concrete Structures of Ministry of Education, Southeast University, No. 2, Sipailou, \\ Nanjing 210096, China \\ ${ }^{2}$ Shanghai Investigation, Design \&Research Institute Co., Ltd.,, No. 388, Yixian Road, Shanghai 200434, China \\ ${ }^{3}$ Key Laboratory of Ministry of Education for Geomechanics and Embankment Engineering, Hohai University, \\ No. 1, Xikang Road, Nanjing 210098, China
}

Correspondence should be addressed to Yongxin Wu; yxwuhhu@163.com

Received 10 June 2021; Revised 1 July 2021; Accepted 23 July 2021; Published 4 August 2021

Academic Editor: Piguang Wang

Copyright ( $\odot 2021$ Bing Li et al. This is an open access article distributed under the Creative Commons Attribution License, which permits unrestricted use, distribution, and reproduction in any medium, provided the original work is properly cited.

The vibration of offshore wind turbines caused by external loads is significant, which will cause fatigue damage to offshore wind turbines. Wind load is the main load during the operation period of the wind turbine, and available studies have shown that the external wind field often exhibits certain non-Gaussian characteristics. This article aims to obtain the fatigue assessment of the monopile foundation of the wind turbine under the non-Gaussian wind fields. A $5 \mathrm{MW}$ wind turbine is selected in this article, and OpenFAST is applied to simulate the wind load. By comparing the Mises stress time histories of the pile foundation at a different depth, the fatigue analysis of the critical spots of the pile foundation is obtained. In the analysis of fatigue damage, the rain flow counting method is adopted, and the two-segment $\mathrm{S}-\mathrm{N}$ curve is selected to analyze the fatigue life of the critical spots. The results show that, by taking the non-Gaussian characteristic of the wind field into account, the fatigue life of the monopile foundation decreases. Therefore, attention should be paid to the influence of non-Gaussian characteristics of wind fields on the fatigue life of monopile-supported wind turbines.

\section{Introduction}

Wind is a clean and renewable source of energy, and it has been identified as a key element to reduce fossil fuel dependency by International Energy Agency. Many wind turbines are installed in offshore areas where the environment during their service life is complex. Wind turbines are affected by environmental loads such as winds, waves, and earthquakes during operation. Wind load is the main external random load borne by offshore wind turbines among them [1-3]. The structural vibration caused by wind load is significant, and the fatigue failure is of great importance. Therefore, it is necessary to study the fatigue damage and fatigue failure of materials at the critical spots of the wind turbine.

In the view of external environmental loads, research studies on fatigue life of wind turbines can be divided into wind load, earthquake $[4,5]$, and combined wind and wave load [3]. An assessment of the fatigue damage of a jacketbased $5 \mathrm{MW}$ offshore wind turbine under the combined wind and wave loads showed that wind load is the main cause of structural fatigue damage of offshore wind turbines [3]. Paulo et al. [6] evaluated the fatigue life of a jacket offshore turbine through static and dynamic analysis and found that the overall fatigue life decreased on average by $11.45 \%$ under the dynamic analysis compared to the static case. When considering the effect of wave nonlinearity on the fatigue damage of large-diameter monopiles of offshore wind turbines, it is shown that the result of a nonlinear wave is $18 \%$ larger than that of the linear wave case [7]. The influence of natural environmental corrosion on the fatigue life of the wind turbine structure is studied by Do et al. [8], and they analyzed the fatigue life of the tower base based on Monte Carlo simulation and multibody dynamics. 
Regarding the direction of the inflow wind, Wang et al. [9] discussed the cumulative fatigue damage value of offshore wind turbine structures under the whole wind direction and single wind direction. Compared with the case of applying unidirectional fatigue load, the turbine under omnidirectional fatigue load is more reasonable. In addition, there are also studies on adding dampers to turbines due to the damper's vibration reduction effect. By adding dampers to the wind turbine, the extending of the fatigue life is successfully achieved [10-12]. For the existing uncoupled model, Xi et al. [13] established a semianalytical model of the aerodynamic damping for horizontal axis wind turbines. The results show that this aerodynamic damping model predicts the dynamic response accurately.

In the perspective of fatigue evaluating methods, scholars have compared multiple analysis methods. Barradas-Berglind and Wisniewski [14] exemplified and compared common fatigue evaluating methods by estimating the fatigue damage at the tower base of the turbine. They put forward and discussed the advantages and disadvantages of each method, as well as their applicability. Six different fatigue damage estimation methods in the frequency domain are compared by Laszlo et al. [15]. They also compared their conclusions with the rain flow counting method in the time domain and recommended three more reliable methods.

Nowadays, research has been conducted on the effects of wind, wave nonlinearity, damping, and fatigue evaluating methods. In previous studies, the simplification of external load is usually cyclic load or random Gaussian load. However, the measured wind speed time series by National Wind Technology Center (NWTC) shows that the wind speed histories at a site did not follow the Gaussian distribution [16], which exhibits non-Gaussian characteristics. Available studies (e.g., [17-19]) based on the non-Gaussian wind fields show that the turbine under non-Gaussian wind exhibits accelerated fatigue damage as compared to the Gaussian case. Therefore, the non-Gaussian characteristic of the wind field needs to be considered. The fatigue damage at the tower base of the wind turbine structure under softening non-Gaussian wind fields is reduced by $9 \%$ compared with the Gaussian case [17]. The non-Gaussian wave load on offshore platforms will accelerate fatigue damage [20]. Ding and Chen [21] proposed a model suitable for hardening nonGaussian, and the applicable extreme value and fatigue evaluation methods are given. The wind-induced vibration of a traffic signal support structure was studied by Ding et al. [22]. They proposed an analytical approach for the fatigue damage and fatigue life assessments for a narrowband, nonGaussian response.

The aforementioned studies have shown that the nonGaussian characteristic of the wind field will reduce the fatigue life of the tower of a wind turbine. However, when considering the non-Gaussian characteristic of the wind fields, these studies did not model the foundation and unable to consider the pile-soil interaction. The structure and foundation interaction should be considered due to the soilpile-tower interaction [23]. Thus, there are no studies on the fatigue damage assessment of a monopile offshore wind turbine when considering the non-Gaussian characteristic of the wind fields. To fill the deficiencies of this research, this paper focuses on the critical spots of the monopile foundation of the wind turbine under the Gaussian and different non-Gaussian wind fields to evaluate the fatigue life of the monopile foundation.

\section{Wind Turbine and Wind Load}

2.1. Wind Turbine Model. The National Renewable Energy Laboratory (NREL) $5 \mathrm{MW}$ wind turbine [24] is selected in this article, and the parameters of the wind turbine are shown in Table 1 . The density of steel is $7850 \mathrm{~kg} / \mathrm{m}^{3}$. If the factors such as paint, bolts, welds, and flanges are considered, it can be equivalent to $8500 \mathrm{~kg} / \mathrm{m}^{3}$ [24]. The diameter and thickness of the pile are $6 \mathrm{~m}$ and $0.06 \mathrm{~m}$, respectively [25]. To accurately consider the flexibility of pile-soil interaction rather than the fixed model, Abaqus is used for modeling. Abaqus is a finite element software for engineering simulation which can model the nonlinear interaction of the soil and pile fluffily. To study the influence of the soil on offshore wind turbines, the soil parameters selected in this article are listed in Table 2. They are two-layer sands [26]. In the finite element method (FEM) model, the nacelle, blades, and hub are simplified as a centralized mass point instead, and the mass and moment of inertia of the simplified part are considered. This mass is connected to the top of the tower with coupled constrain.

The length and width of the soil are $120 \mathrm{~m}$ and the depth is $80 \mathrm{~m}$. The grid size of the soil is $3 \times 3 \times 3 \mathrm{~m}$. Partial mesh densification is performed at the pile-soil contact area, and the grid size near the pile is $1.5 \times 1.5 \times 1.5 \mathrm{~m}$. C3D8R elements (solid elements) are used for soil elements. The grid vertical spacing of the pile and tower is $2 \mathrm{~m}$. In order to set up contact with the soil better, the pile and tower also use the C3D8R elements. The model has a total of 46784 elements. To simulate the nonlinear interaction between pile and soil, "friction" contact is set between pile and soil, where "hard" contact is selected for normal direction and "Coulomb" friction contact is selected for tangential direction. The "tie" constraint is adopted between the pile and the tower to make their displacement consistent. For the constraints, the side of the soil is horizontally restricted, the bottom of the soil is fixed, and there are no constraints on the upper surface of the soil. Figure 1 shows the mesh of the model and the relative position of the pile and soil. The zero point in the vertical direction $(z=0 \mathrm{~m})$ is at the mean sea level (MSL), that is, the mudline is located at $z=-20 \mathrm{~m}$ and the tower base is located at $z=10 \mathrm{~m}$.

The force acting on the blade and the rotor is simplified as the concentrated force rot thrust acting at the height of the rotor $(z=90 \mathrm{~m})$. The tower is divided into five sections, the length of each section is $15.52 \mathrm{~m}$, and the wind load on each section is converted into a concentrated force acting on points RP-1 RP-5. The heights of RP-1 to RP-5 are $17.76 \mathrm{~m}$, $33.28 \mathrm{~m}, 48.8 \mathrm{~m}, 64.32 \mathrm{~m}$, and $79.84 \mathrm{~m}$ respectively.

The verification of the model is the modal analysis, which calculates the first few natural frequencies of the model. The natural frequency of the model is given in Table 3 . The rated rotor speed of the wind turbine is $12.1 \mathrm{rpm}$, and the 
TABLE 1: Parameters of an offshore wind turbine.

\begin{tabular}{lc}
\hline Properties & NREL 5 \\
& MW OWT \\
\hline Rating & $5 \mathrm{MW}$ \\
Rotor, hub diameter (m) & 126,3 \\
Hub height (m) & 90 \\
Cut-in, cut-out wind speed (m/s) & 3,25 \\
Rated wind speed (m/s) & 11.4 \\
Cut-in, rated rotor speed (rpm) & $6.9,12.1$ \\
Rotor mass $(\mathrm{kg})$ & 110000 \\
Nacelle mass $(\mathrm{kg})$ & 240000 \\
Tower mass $(\mathrm{kg})$ & 347460 \\
Water depth $(\mathrm{m})$ & 20 \\
Tower height $(\mathrm{m})$ & 90 \\
Monopile length $(\mathrm{m})$ & 60 \\
Top of tower diameter and thickness $(\mathrm{m})$ & $3.87,0.019$ \\
Bottom of tower diameter and thickness $(\mathrm{m})$ & $6,0.027$ \\
Monopile diameter and thickness $(\mathrm{m})$ & $6,0.06$ \\
Density of tower and monopole $\left(\mathrm{kg} / \mathrm{m}^{3}\right)$ & 8500 \\
Yang's modulus of tower and monopile $(\mathrm{GPa})$ & 210 \\
\hline
\end{tabular}

corresponding frequency is $0.2017 \mathrm{~Hz}$. The resonance phenomenon is one of the main problems of OWT on the monopile support structure. To avoid this phenomenon, the first natural frequency $f_{1}$ of the supporting structure should be sufficiently separated from the rotating rotor induction frequency $f 1 \mathrm{P}$ and the blade passing frequency $f 3 \mathrm{P}$. According to the GL standard [27], the first natural frequency should avoid the rotor induction frequency with a tolerance of $5 \%$, expressed as

$$
f_{1 P+0.05}<f_{1}<f_{3 P-0.05} .
$$

For the $5 \mathrm{MW}$ wind turbine, the resonance constraints could be expressed by [28]

$$
0.212 \mathrm{~Hz}<f_{1}<0.328 \mathrm{~Hz} \text {. }
$$

In this article, the first-order frequencies of the FEM model in this article is $0.258 \mathrm{~Hz}$, which is not within the influence range of resonance frequency. For instance, the FEM model of the offshore wind turbine in this article will not resonate during operation, and the dynamic response analysis can be carried out based on this model.

2.2. Wind Load Simulation. TurbSim [29] is open-source software, which can generate three-dimensional (downwind, crosswind, and vertical wind direction) turbulent wind fields. It can generate wind fields based on different power spectral density (PSD) functions. The PSD function used in this article is the Kamal spectrum in the IEC61400 [30]. The turbulence model is the normal turbulence model (NTM). Figure 2 shows the mesh of the wind field. There are $31 \times 31$ nodes on the area of blade rotation and another 4 nodes on the tower. The wind turbine hub is located in the center of the grid.

Existing studies usually simplify the wind field to a stationary random Gaussian process. This simplification is valid in the plains where the terrain is flat and the wind flow is relatively stable. However, in a complex ocean environment, this assumption is quite different from the actual situation [31], so the non-Gaussian nature of offshore wind fields needs to be considered. The difference between Gaussian distribution and non-Gaussian distribution is mainly manifested in higher-order statistical moments, such as skewness $\left(\gamma_{3}\right)$ and kurtosis $\left(\gamma_{4}\right)$.

The wind field obtained through TurbSim is a Gaussian wind field, and it needs to be converted into a non-Gaussian wind field. There is no universal method to simulate a nonGaussian process with a specified skewness and kurtosis. The probability density function (PDF) of a non-Gaussian is so sophisticated that it cannot be represented by a formula with parameters. The translation method is usually used to translate a Gaussian process to a non-Gaussian process. The Hermite translation model [21, 32-34] is used in this article. In this article, the skewness and kurtosis pairs of nonGaussian wind $\left(\gamma_{3}, \gamma_{4}\right)$ selected are $(0,5)(0,7)$. Each wind speed bin of Gaussian and non-Gaussian wind field is simulated through the same random seed. The simulated wind speeds are $4-24 \mathrm{~m} / \mathrm{s}$ at a bin of $2 \mathrm{~m} / \mathrm{s}$, and there are a total of 11 wind speed series. Each wind speed is simulated 30 times. An example of the wind speed time histories at $12 \mathrm{~m} / \mathrm{s}$ is shown in Figure 3 .

To verify the accuracy of the wind fields, the frequency domain characteristics are also analyzed. The PSD curves and the target IECKAI PSD curve of Figure 3 are shown in Figure 4. The result shows that the PSD curve of the simulated wind field is close to the target PSD curve, which means the transformation of the wind field is reasonable.

After simulating the full wind field, the total wind force is calculated by OpenFAST $[35,36]$, which is an open-source software based on the aerodynamic coupling model and multibody dynamics. The main advantage of this software is that it can consider the effect of the control system. The wind load acting on the blade is calculated by the beam element momentum (BEM) theory, and then their resultant force is converted into a concentrated force acting on the rotor. For the wind acting on the tower, the linear load of each section of the tower is transformed into a concentrated load too. An example of rot thrust and the force at tower height $48.8 \mathrm{~m}$ is shown in Figure 5.

\section{Fatigue Analysis in the Time Domain}

3.1. Classification of Fatigue. Metal materials will produce fatigue failure under the action of alternating stress. There are two main forms of fatigue failure: low-cycle fatigue (LCF) and high-cycle fatigue (HCF) [37, 38]. Strain fatigue failure belongs to LCF which is characterized by greater strain during failure, and the number of cycles of load before failure is about $10^{4}$. Cracks occur in the early stages of fatigue life, which is generally less than $3 \%-10 \%$ of the fatigue life, after which there is a long period of crack propagation [39]. Structural failure under seismic load is a typical strain fatigue failure. Stress fatigue failure belongs to HCF. Its characteristic is that the alternating stress experienced by the material is generally far less than the yield limit, but it is subjected to high-cycle cyclic stress before failure, and the number of cycles is about $10^{4} \sim 10^{7}$. Fatigue failure under 
TABLE 2: Soil parameters in Abaqus model.

\begin{tabular}{lcccccc}
\hline & $\gamma^{\prime}\left(\mathrm{kN} / \mathrm{m}^{3}\right)$ & $\mathrm{c}(\mathrm{kPa})$ & $\varphi\left({ }^{\circ}\right)$ & Yang's modulus $(\mathrm{MPa})$ & Poisson's ratio & Depth $(\mathrm{m})$ \\
\hline Sand 1 & 10 & 0.1 & 35 & 40 & 0.3 & 0.3 \\
Sand 2 & 10 & 0.1 & 37.5 & 90 & 60 \\
\hline
\end{tabular}

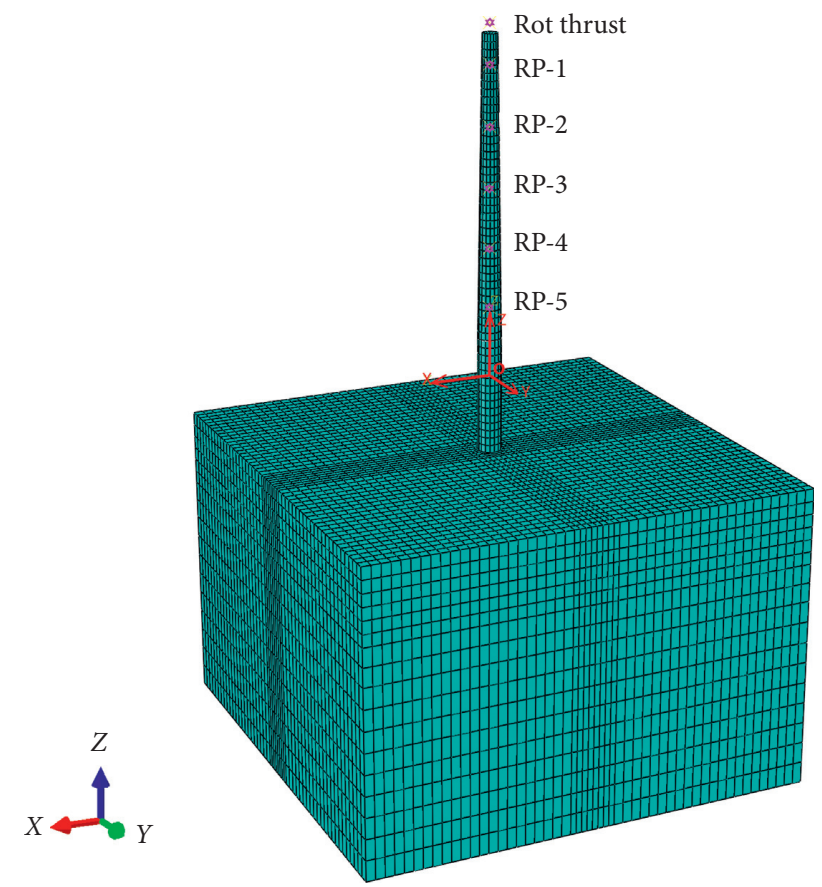

FIgURE 1: The model of offshore wind turbine.

random wind load or wave load is a typical stress fatigue failure. In addition, the fatigue life of more than $10^{7}$ cycles is called very high-cycle fatigue (VHCF) [40].

3.2. Rain-Flow Counting Method. For the foundation of the offshore wind turbines, its fatigue damage is typical highcycle fatigue damage when random wind load is transferred from the tower to the pile foundation. The stress histories at different sections of the monopile of the turbine under Gaussian and non-Gaussian wind fields are obtained. These stress histories are disorderly and cannot be directly used in the fatigue failure analysis of materials. A certain method should be used to deal with it.

The rain flow counting (RFC) method was proposed by British engineers Matsuishi M. and Endo T. in the 1950s [41]. Its function is to simplify the stress series into several load cycles with different stress amplitudes, and then the simplified load cycles are used for subsequent fatigue damage assessment and fatigue life estimation. It is based on the two-parameter method, considering two variables of dynamic strength (amplitude) and static strength (mean), which conforms to the inherent characteristics of fatigue load. The rain flow counting method is mainly used in engineering, especially in fatigue life calculation [42-44].

Before calculating the fatigue damage, it is necessary to count the stress time history of the wind turbine at critical spots through the RFC method. Then, the number of cycles of the stress amplitude and the corresponding mean stress value is obtained. As shown in Figure 6, the RFC method simplifies the disordered structural stress histories into several different stress amplitudes and counts the number. It takes the time axis as the horizontal axis and the stress axis as the vertical axis. The process of applying the counting method to the statistics of the above two parameters on the time history curve likes the process of rain flowing down from the roof.

3.3. S-NCurve. Several standard specimens are used to carry out fatigue experiments under the conditions of a certain average stress $\sigma_{m}$ and different stress amplitudes $\sigma_{a}$. This experiment tests the number of cycles $N$ when the specimen is broken. Then, plot the experimental results in a coordinate system with modified stress $\mathrm{S}$ and cycles of number $N$, and the connection of a series of points is the S-N curve. S-N curves generally have four types: exponential function formula, power function formula, Basquin formula, and Weibull formula. Among them, the power function formula [45] is widely used in current engineering practice.

The power function from the $\mathrm{S}-\mathrm{N}$ curve expression is as follows:

$$
N S^{m}=A
$$

Take the logarithm of both sides:

$$
\lg N=\lg A-m \lg S \text {. }
$$

In the formula, $S$ and $A$ are parameters related to material properties, which can be obtained by curve fitting.

When the material works in different environments, the $\mathrm{S}-\mathrm{N}$ curve is different. The objective of this article is the large-diameter hollow steel pipe pile. The double-slope S-N curve should be selected after considering the wall thickness effect. In combination with the position of the mudline of the monopile foundation of the turbine being located below sea level, the corrosion effect of seawater should be considered in the fatigue analysis. In summary, this article selects the D-type two-stage S-N curve (Figure 7) [46].

3.4. Linear Cumulative Damage Theory. After the rain flow counting method is used to obtain the frequency of the stress amplitude and the corresponding mean value, the equivalent stress amplitude is calculated according to the PalmgrenMiner criterion [47, 48]:

$$
S_{\text {reff }}^{0}=\sqrt[3]{\sum_{i} f_{i} S_{r i}^{3}}
$$

where $S_{r i}$ represents the stress amplitude and $f_{i}$ is the corresponding frequency. 
TABle 3: The first 10 order natural frequencies of the model $(\mathrm{Hz})$.

\begin{tabular}{lcccccccccc}
\hline Order & 1 & 2 & 3 & 4 & 5 & 6 & 7 & 8 & 9 & 10 \\
\hline Natural frequency & 0.258 & 0.259 & 0.821 & 0.862 & 0.862 & 1.031 & 1.162 & 1.165 & 1.230 & 1.239 \\
\hline
\end{tabular}

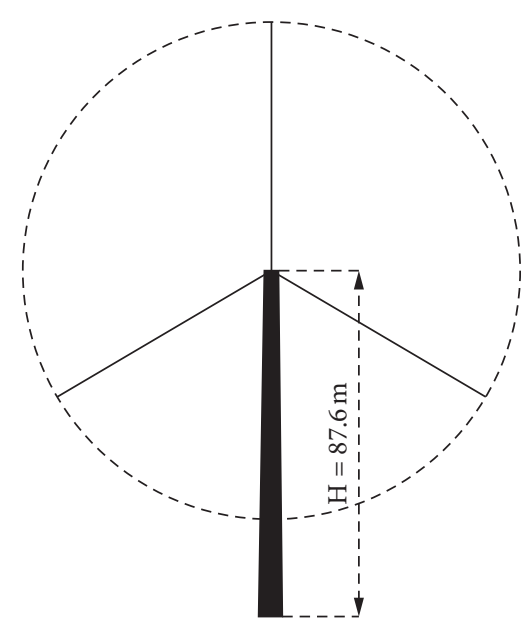

(a)

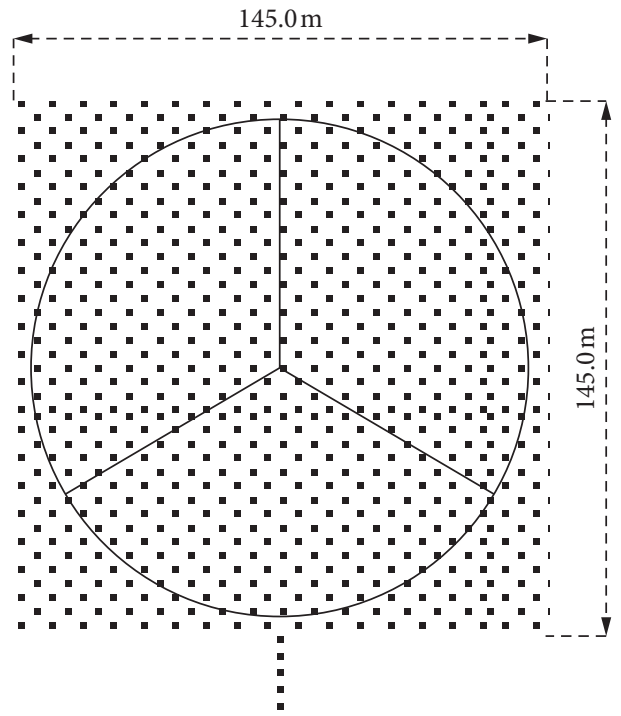

(b)

Figure 2: (a) Wind turbine model. (b) Mesh of the wind field.

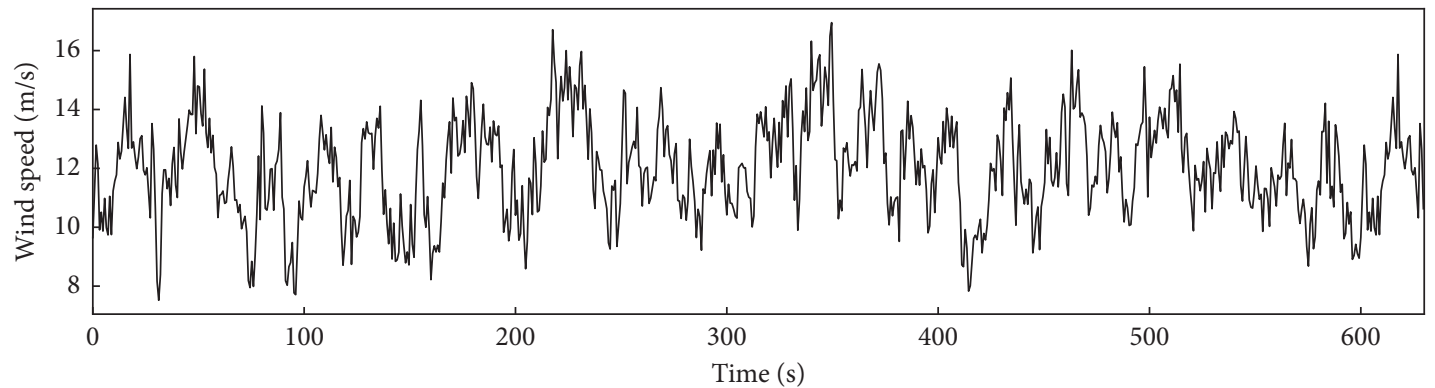

(a)

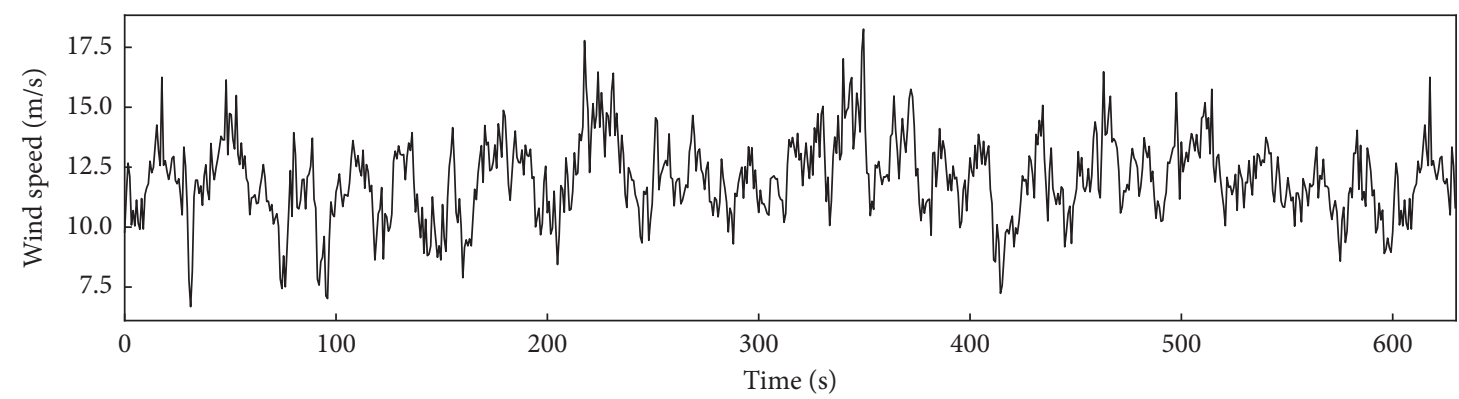

(b)

Figure 3: Continued. 


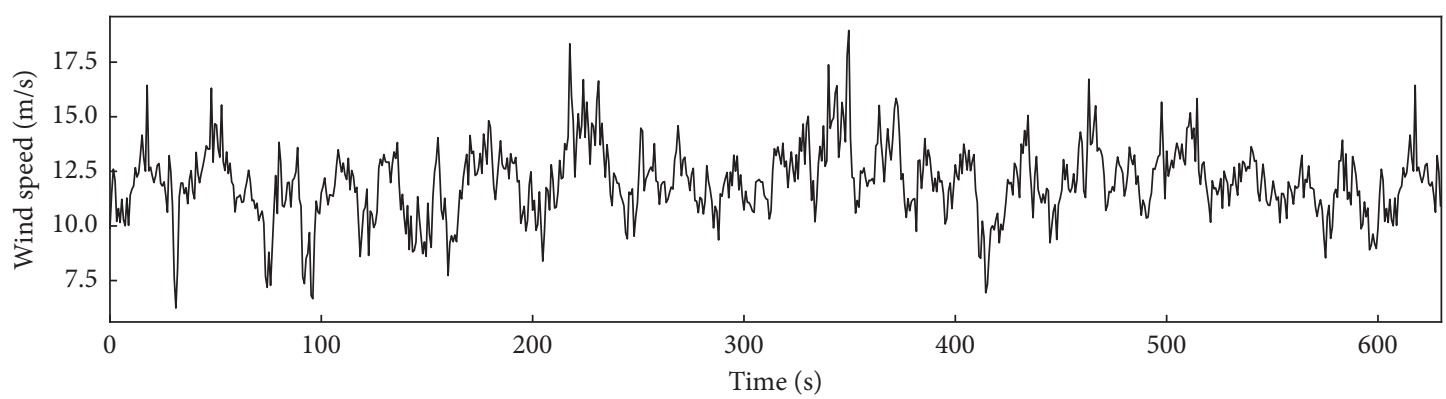

(c)

FIgURE 3: Simulated wind speed time histories at the hub height: (a) $(0,3)$ wind field, (b) $(0,5)$ wind field, and (c) $(0,7)$ wind field.

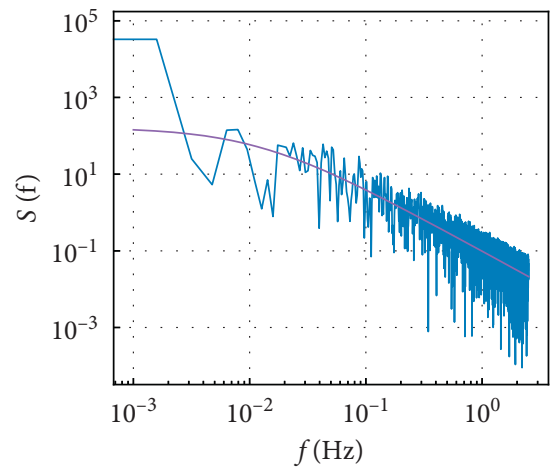

- $(0,3)$ wind field

Kaimal spectrum

(a)

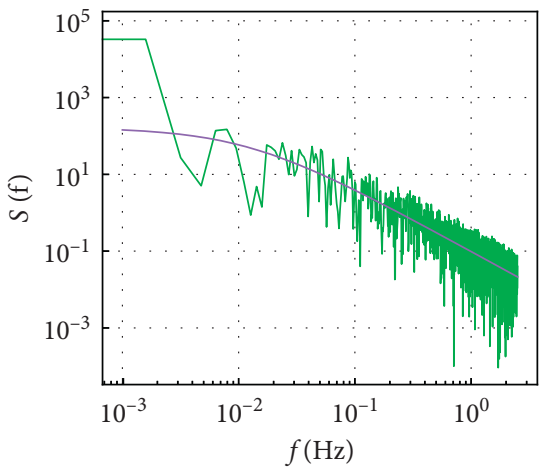

$(0,5)$ wind field

_ Kaimal spectrum

(b)

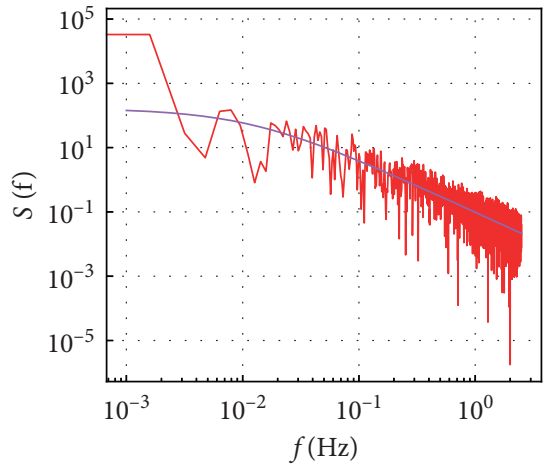

$(0,7)$ wind field

- Kaimal spectrum

(c)

Figure 4: Simulated spectrum and target spectrum. (a) PSD for $(0,3)$. (b) PSD for $(0,5)$. (c) PSD for $(0,7)$.

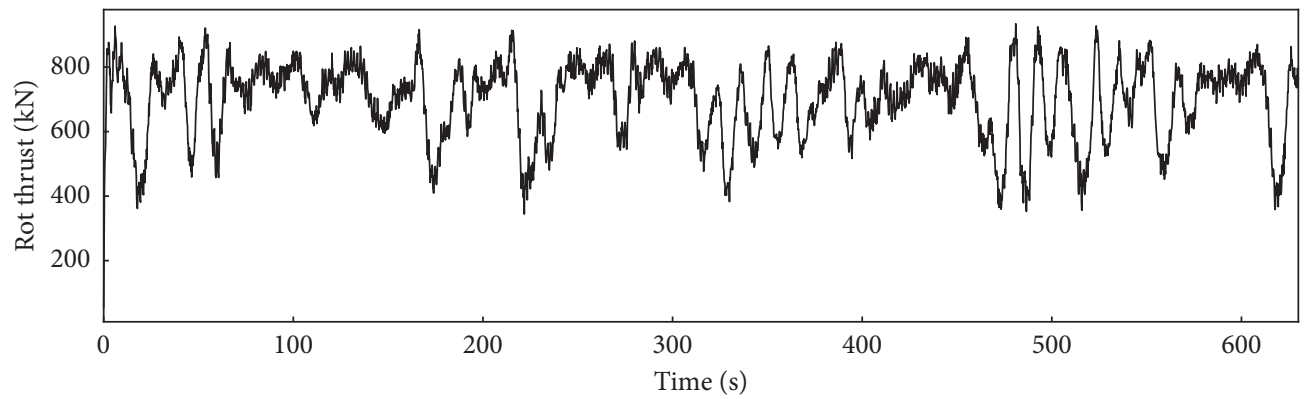

(a)

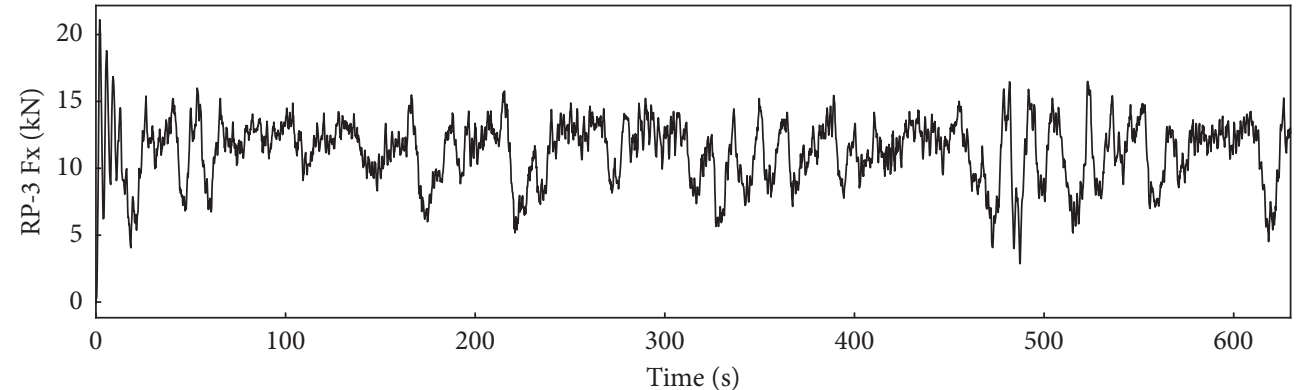

(b)

Figure 5: An example of wind force at different positions. (a) Rot thrust at wind speed $12 \mathrm{~m} / \mathrm{s}$. (b) Linear load at RP-3. 


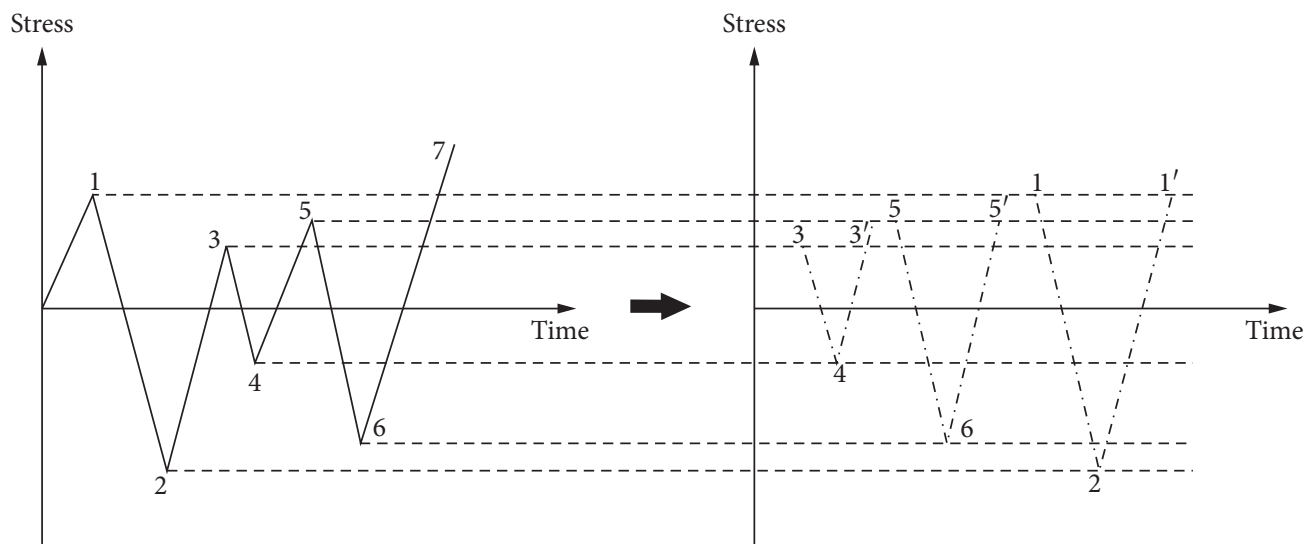

Figure 6: Principle of rain flow counting method.

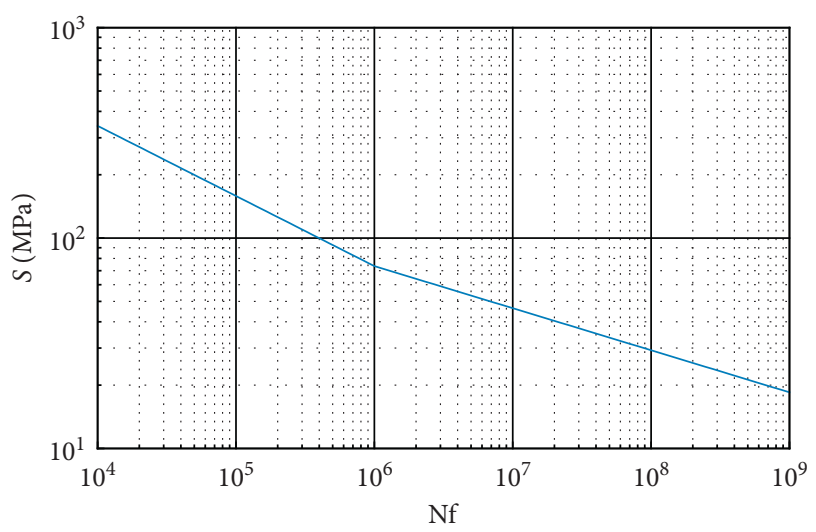

Figure 7: D-type two-segment S-N curve.

To consider the influence of the mean stress, the equivalent fatigue life curve is usually used to convert the fatigue life of different mean stress and stress amplitude. Three kinds of curves can describe the relationship between cyclic stress amplitude and mean stress, namely the Soderberg formula, Goodman formula, and Gerber formula.

Among them, Goodman's empirical formula is simple in form and can be applied to various brittle materials and metal materials. This article uses Goodman's formula to describe the relationship between the stress amplitude and the average stress for conversion. The 0 mean stress process is transformed into a stress process with the mean stress value $S_{m}$ according to Goodman's criterion [47]:

$$
S_{\text {reff }}=S_{\text {reff }}^{0} \cdot\left(1-\frac{S_{m}}{S_{u}}\right)^{-1},
$$

where $S_{\text {reff }}^{0}$ is the equivalent stress amplitude when the mean stress value is $0, S_{\text {reff }}$ is the equivalent stress amplitude when the mean stress value is $S_{m}$, and $S_{u}$ is the ultimate strength of materials.

When calculating the fatigue life of the wind turbine at the critical spots, the number of stress cycles under the action of the equivalent stress amplitude is expressed as $[10,46]$

$$
\lg N_{f}=\lg a-m \lg \left(S_{\text {reff }} \times\left(\frac{t}{t_{\text {ref }}}\right)^{k}\right)
$$

where $a$ and $m$ are the parameters of the S-N curve. For the D-type two-segment S-N curve referenced by DNV-RPC203, when $N_{f}<10^{6}, m=3, \lg a=11.764$, when $N_{f}>10^{6}$, $m=5, \lg a=15.606, t_{\text {ref }}=32 \mathrm{~mm}, k=0.2$, and $t=60 \mathrm{~mm}$ which is the pile thickness in this article.

After the corresponding fatigue curve is obtained, the Miner linear fatigue damage accumulation theory can be used to calculate the corresponding fatigue. The specific formula is as follows:

$$
D=\sum \frac{n_{i}}{N_{i}}
$$

where $n_{i}$ is the number of constant amplitude stress range cycles at different wind speeds and $N_{i}$ is the total number of stress cycles. When $D$ reaches 1 , it means that the material has reached the fatigue limit state.

\section{Fatigue Life at Critical Spots}

4.1. Critical Spots for Fatigue Analysis. To calculate fatigue damage, the corresponding fatigue conditions must be determined first according to the load characteristics. At present, fatigue damage analysis has two kinds of ideas for selecting the load conditions of omnidirectional incoming load and unidirectional incoming load. In this article, the natural environmental excitations of offshore wind turbines are mainly wind load. Since this article focuses on the effect of the non-Gaussian characteristic of wind field on the fatigue damage of offshore wind turbine foundations, only the positive $x$-axis is selected as the angle of incidence for structural fatigue analysis, and the influence of different incident angles is not considered.

To determine the location of the maximum fatigue damage of a monopile, this article compares the stress time history curves of the monopile foundation at 5 different locations. They are at the height of $0 \mathrm{~m}$ (mean sea level), $-10 \mathrm{~m},-20 \mathrm{~m}$ (mudline surface), $-30 \mathrm{~m}$, and $-40 \mathrm{~m}$. The 
Mises stress histories with the period of $600 \mathrm{~s}$ in the $x$-direction at these different locations over time are shown in Figure 8 . The mean stress and the standard derivation of these five positions are listed in Table 4. It can be noted that, at the mudline surface of the pile foundation $(z=-20 \mathrm{~m})$, the time history of the Mises stress is the largest and the variation amplitude is the largest too. Therefore, this article selects the stress at the mudline surface $(z=-20 \mathrm{~m})$ of the pile foundation as the critical spots.

4.2. Fatigue Damage at Critical Spots. At the mudline surface of the monopile foundation, the stress time history is counted and counted by the rain flow counting method, and multiple rain flow counting matrices are obtained. Taking the wind speed of $8 \mathrm{~m} / \mathrm{s}$ as an example, the rain flow counting matrix under three different wind fields is shown in Figure 9. These figures show that the stress amplitude of rain flow counting is mostly concentrated in the interval of $0-10 \mathrm{MPa}$.

After the rain flow counting matrix is obtained, the probability of occurrence of each (stress amplitude, mean stress) pair can be calculated. Using the linear cumulative damage theory mentioned in Section 3.4, the calculated modified equivalent stress amplitude changes with wind speed as shown in Figure 10(a). The corresponding fatigue damage is shown in Figure 10(b).

In general, as the wind speed increases, the equivalent stress amplitude also increases. The equivalent stress amplitude under $(0,5)$ and $(0,7)$ wind fields is larger than the equivalent stress amplitude under $(0,3)$ wind fields. But the difference is not significant, and the maximum deviation is below $5 \%$. After the wind speed is greater than $18 \mathrm{~m} / \mathrm{s}$, the non-Gaussian characteristic of the wind field has a limited effect on the equivalent stress amplitude, and the equivalent stress amplitude is almost the same in the three cases. The fatigue damage value also shows a similar characteristic. Table 5 and Figure 10(b) show the fatigue damage value under different wind speeds. In the case of wind speeds less than $10 \mathrm{~m} / \mathrm{s}$, the fatigue damage rate at the critical spots is extremely small regardless of whether it is Gaussian or nonGaussian. At a wind speed of $12-16 \mathrm{~m} / \mathrm{s}$, the fatigue damage rate begins to enter a slow-growth stage. When the wind speed is greater than $18 \mathrm{~m} / \mathrm{s}$, the fatigue damage rate increases rapidly. Comparing the difference between the non-Gaussian wind field and the Gaussian wind field, it can be found that when the wind speed is less than $18 \mathrm{~m} / \mathrm{s}$, the difference in damage between the non-Gaussian wind field and the Gaussian wind field is larger, and the regular pattern is not very obvious. When the wind speed is greater than $18 \mathrm{~m} / \mathrm{s}$, the difference between these three conditions is small.

\subsection{Fatigue Life under Different Annual Average Wind Speed.} To study the long-term non-Gaussian wind field, consider the long-term fatigue damage of the wind turbine under different annual mean wind speeds $u_{\text {ave }}$ in a certain location.

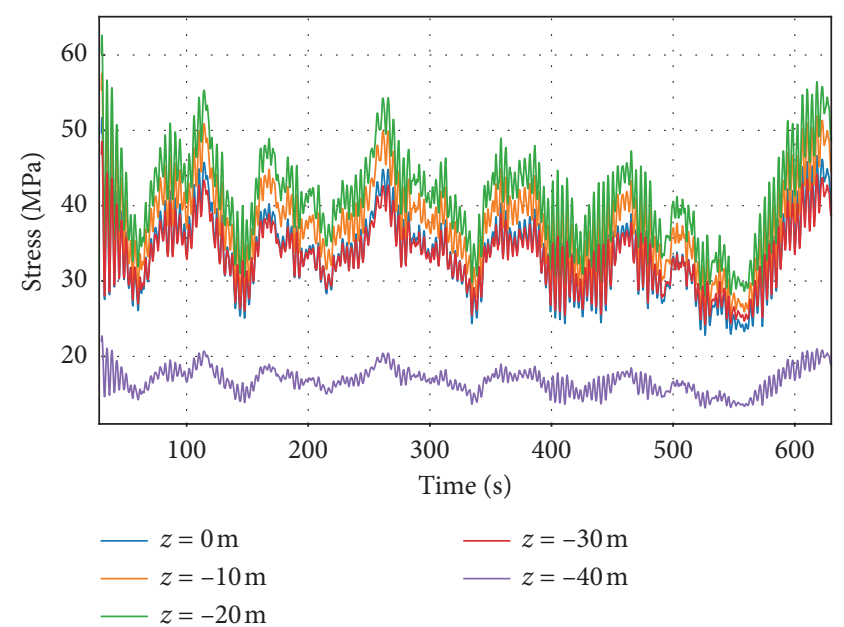

Figure 8: Stress histories at 5 different positions of monopile.

Table 4: Comparison between five different positions (MPa).

\begin{tabular}{lccccc}
\hline & $z=0 \mathrm{~m}$ & $z=-10 \mathrm{~m}$ & $z=-20 \mathrm{~m}$ & $z=-30 \mathrm{~m}$ & $z=-40 \mathrm{~m}$ \\
\hline $\begin{array}{l}\text { Mean } \\
\begin{array}{l}\text { Standard } \\
\text { derivation }\end{array}\end{array}$ & 33.17 & 37.50 & 41.02 & 33.37 & 16.76 \\
\hline
\end{tabular}

Assuming that the distribution of wind speed in a year is simplified by following the Rayleigh distribution, the probability density function (PDF) is

$$
f(u)=\frac{\pi u}{2 u_{\mathrm{ave}}^{2}} \times \exp \left(-\pi\left(\frac{u}{2 u_{\mathrm{ave}}}\right)^{2}\right) .
$$

The damage $D$ in one year is

$$
D=\int D_{i}(u) f(u) \mathrm{d} u=\sum_{j=1}^{N} D_{i}(u) f(u),
$$

when the cumulative damage $D=1$, it is deemed that the wind turbine has reached the fatigue life. Figure 11 investigates the locations where the annual mean wind speed varies from $5 \mathrm{~m} / \mathrm{s}$ to $10 \mathrm{~m} / \mathrm{s}$. The fatigue life of annual mean wind speeds $5 \mathrm{~m} / \mathrm{s}$ to $9 \mathrm{~m} / \mathrm{s}$ is illustrated in Table 6 .

It can be found that, after taking the non-Gaussian characteristic of the wind field into account, the fatigue life of the wind turbine has a trend of decreasing. Among them, at an annual mean wind speed of $5 \mathrm{~m} / \mathrm{s}$, the fatigue life is reduced by $10 \%$. At an annual mean wind speed of $9 \mathrm{~m} / \mathrm{s}$, the fatigue life is reduced by about $5 \%$. And, there is a trend that the greater the kurtosis, the greater the degree of fatigue life reduction. Therefore, in the areas with complex environments, especially when the wind field has strong nonGaussian characteristics, attention should be paid to the impact of wind field non-Gaussian properties on the fatigue life of monopile of the offshore wind turbine. 


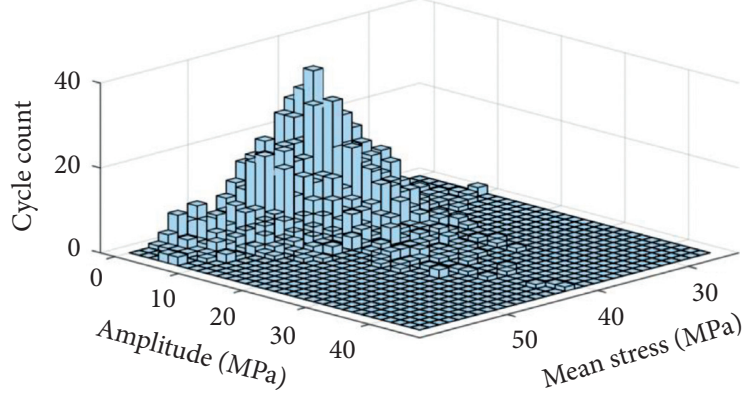

(a)

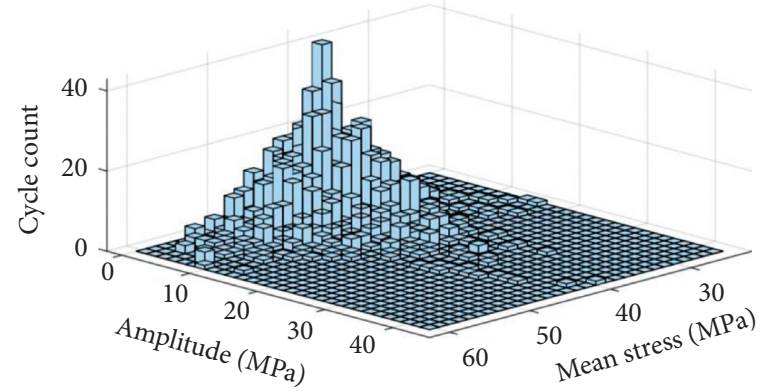

(b)

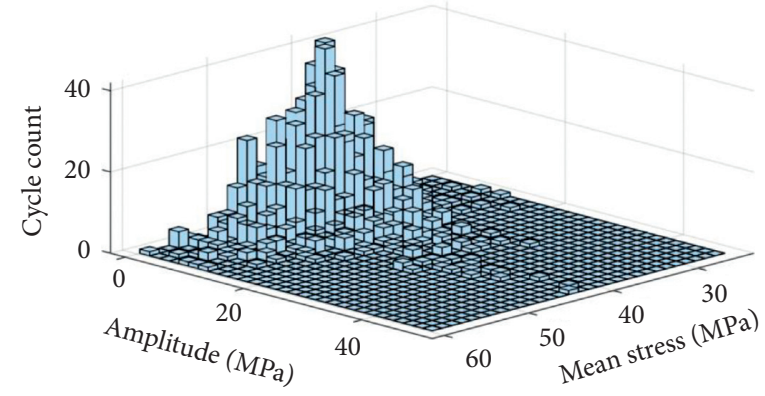

(c)

Figure 9: Rain flow counting matrix under different wind fields $(8 \mathrm{~m} / \mathrm{s})$ : (a) $(0,3)$. (b) $(0,5)$. (c) $(0,7)$.

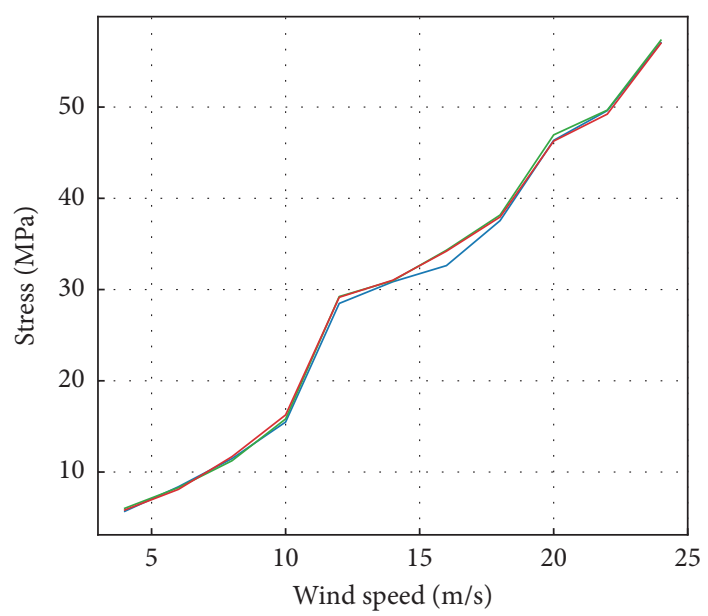

$-(0,3)$
$-(0,5)$
$-(0,7)$
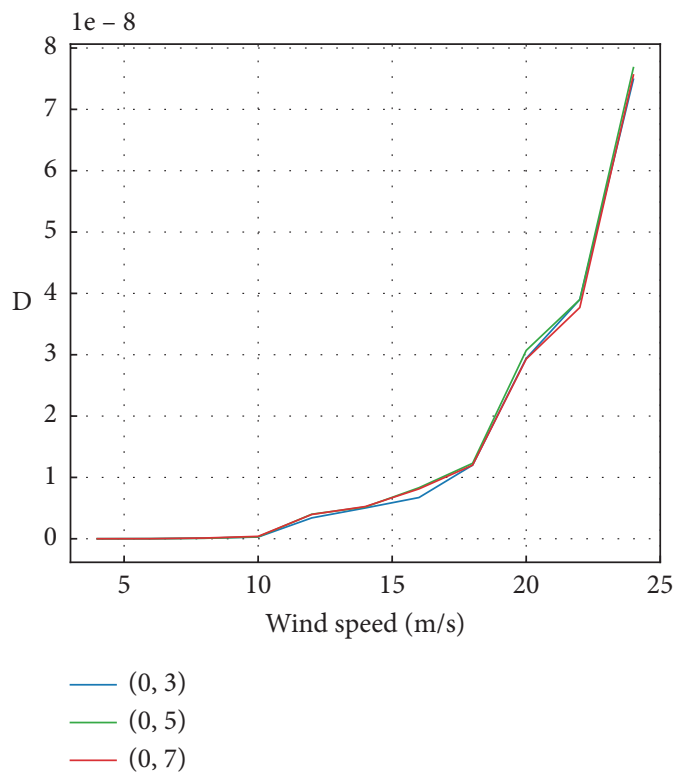

(a)

(b)

FIgURE 10: Equivalent stress amplitude and fatigue damage at mudline ( $-20 \mathrm{~m})$ of the monopile. (a) Equivalent stress amplitude. (b) Fatigue damage. 
TABle 5: Fatigue damage value under different wind speeds.

\begin{tabular}{lccccc}
\hline Wind speed $(\mathrm{m} / \mathrm{s})$ & $(0,3)$ wind field & $(0,5)$ wind field & $(0,7)$ wind field & $\begin{array}{c}\text { Difference } \\
\text { between }(0,3) \text { and }(0,5)\end{array}$ & $\begin{array}{c}\text { Difference } \\
\text { between }(0,3) \text { and }(0,7)\end{array}$ \\
\hline 4 & $2.055 E-12$ & $3.114 E-12$ & $2.282 E-12$ & 51.5 & 11.0 \\
6 & $1.495 E-11$ & $1.426 E-11$ & $1.177 E-11$ & -4.6 & -21.3 \\
8 & $9.692 E-11$ & $7.523 E-11$ & $1.207 E-10$ & -22.4 & 24.5 \\
10 & $2.813 E-10$ & $3.138 E-10$ & $3.907 E-10$ & 11.6 & 38.9 \\
12 & $3.404 E-09$ & $4.001 E-09$ & $3.965 E-09$ & 3.5 & 4.3 \\
14 & $5.018 E-09$ & $5.183 E-09$ & $5.247 E-09$ & 23.7 & 2.6 \\
16 & $6.724 E-09$ & $8.316 E-09$ & $8.127 E-09$ & 2.4 & -0.2 \\
18 & $1.199 E-08$ & $1.227 E-08$ & $1.196 E-08$ & 4.2 & -0.3 \\
20 & $2.942 E-08$ & $3.065 E-08$ & $2.931 E-08$ & 0.2 & -3.2 \\
22 & $3.898 E-08$ & $3.904 E-08$ & $3.772 E-08$ & 2.6 & 1.0 \\
24 & $7.486 E-08$ & $7.680 E-08$ & $7.560 E-08$ & & \\
\hline
\end{tabular}

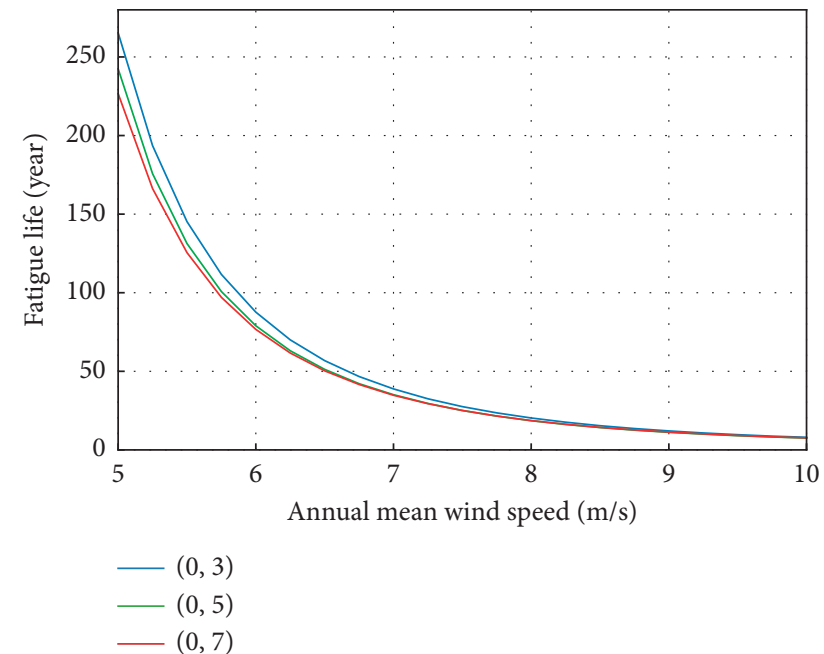

Figure 11: Fatigue life under different annual mean wind speed.

TABLe 6: Fatigue life under annual mean wind speed (year).

\begin{tabular}{lccc}
\hline$u_{\text {ave }}(\mathrm{m} / \mathrm{s})$ & $(0,3)$ & $(0,5)$ & $(0,7)$ \\
\hline 5 & 265.3 & 242.4 & 226.7 \\
7 & 38.7 & 35.1 & 34.8 \\
9 & 12.0 & 11.2 & 11.3 \\
\hline
\end{tabular}

\section{Conclusion and Remarks}

This article is based on the joint modeling of TurbSim, OpenFAST, and Abaqus. The fatigue assessment of the monopile foundation of offshore wind turbine under the Gaussian and non-Gaussian wind fields is analyzed. The main conclusions are as follows:

(1) Under the non-Gaussian wind field, the fatigue damage of the monopile foundation is different from that of a Gaussian wind field. When the wind speed is lower than $18 \mathrm{~m} / \mathrm{s}$, this difference is significant. And, in most cases, the fatigue damage under the nonGaussian wind field is greater than that of the Gaussian case under the same wind speed. When the wind speed is higher than $18 \mathrm{~m} / \mathrm{s}$, the difference is not obvious.
(2) The non-Gaussian characteristic of the wind field also has a greater impact on the long-term fatigue life. When the annual mean wind speed is $5 \mathrm{~m} / \mathrm{s}$, the fatigue life is reduced by $10 \%$. At an annual mean wind speed of $9 \mathrm{~m} / \mathrm{s}$, the life span is reduced by about $5 \%$. Comparing with the Gaussian case, as the kurtosis increases, the fatigue life also tends to gradually decrease. Thus, attention should be paid to the impact of wind field non-Gaussian properties on the fatigue life of monopile of the offshore wind turbine.

\section{Data Availability}

The data used to support the findings of this study are available from the corresponding author upon request.

\section{Conflicts of Interest}

The authors declare that they have no conflicts of interest.

\section{Acknowledgments}

The supports by the National Natural Science Foundation of China (grant no. 51578145) are greatly acknowledged.

\section{References}

[1] T. T. Tran, G. J. Ryu, Y. H. Kim, and D. H. Kim, "CFD-based design load analysis of 5MW offshore wind turbine," AIP Conference Proceedings, vol. 1493, no. 1, pp. 533-545, 2012.

[2] P. Wang, M. Zhao, X. Du, J. Liu, and C. Xu, "Wind, wave and earthquake responses of offshore wind turbine on monopile foundation in clay," Soil Dynamics and Earthquake Engineering, vol. 113, pp. 47-57, 2018.

[3] D. Wenbin, M. Torgeir, and G. Zhen, "Fatigue reliability analysis of the jacket support structure for offshore wind turbine considering the effect of corrosion and inspection," Reliability Engineering \& System Safety, vol. 106, pp. 11-27, 2012.

[4] P. Wang, Y. Xu, X. Zhang, R. Xi, and X. Du, "A substructure method for seismic responses of offshore wind turbine considering nonlinear pile-soil dynamic interaction," Soil Dynamics and Earthquake Engineering, vol. 144, Article ID 106844, 2021. 
[5] G. Zhang, P. Wang, M. Zhao, X. Du, and X. Zhao, "Seismic structure-water-sediment-rock interaction model and its application to immersed tunnel analysis under obliquely incident earthquake," Tunnelling and Underground Space Technology, vol. 109, Article ID 103758, 2021.

[6] P. Mendes, J. A. F. O. Correia, A. Mourão, and R. Pereira, "Fatigue assessments of a jacket-type offshore structure based on static and dynamic analyses," Practice Periodical on Structural Design and Construction, vol. 26, no. 1, Article ID 04020054, 2021.

[7] S. Schløer, H. Bredmose, and H. B. Bingham, "The influence of fully nonlinear wave forces on aero-hydro-elastic calculations of monopile wind turbines," Marine Structures, vol. 50, pp. 162-188, 2016.

[8] T. Q. Do, H. Mahmoud, and J. W. v. d. Lindt, "Fatigue life of wind turbine tower bases throughout Colorado," Journal of Performance of Constructed Facilities, vol. 4, Article ID 04014109, 2014.

[9] B. Wang, Y. Li, J. Luo, D. Wang, and S. Zhao, "Analysis of fatigue damage for offshore wind turbine Substructure," Applied Mechanics and Materials, vol. 454, pp. 7-14, 2014.

[10] R. Rezaei, P. Fromme, and P. Duffour, "Fatigue life sensitivity of monopile-supported offshore wind turbines to damping," Renewable Energy, vol. 123, pp. 450-459, 2018.

[11] S.-H. Ju and Y.-C. Huang, "MTMD to increase fatigue life for OWT jacket structures using Powell's method," Marine Structures, vol. 71, Article ID 102726, 2020.

[12] S. Colwell and B. Basu, "Tuned liquid column dampers in offshore wind turbines for structural control," Engineering Structures, vol. 31, no. 2, pp. 358-368, 2009.

[13] R. Xi, P. Wang, X. Du, K. Xu, C. Xu, and J. Jia, "A semianalytical model of aerodynamic damping for horizontal axis wind turbines and its applications," Ocean Engineering, vol. 214, Article ID 107861, 2020.

[14] J. J. Barradas-Berglind and R. Wisniewski, "Representation of fatigue for wind turbine control," Wind Energy, vol. 19, no. 12, pp. 2189-2203, 2016.

[15] L. Arany, S. Bhattacharya, J. Macdonald, and S. J. Hogan, "Accuracy of frequency domain fatigue damage estimation methods for offshore wind turbine support structures," in Proceedings of the Second International Conference on Vulnerability and Risk Analysis and Management (ICVRAM) and the Sixth International Symposium on Uncertainty, Modeling, and Analysis (ISUMA), pp. 1293-1302, Liverpool, UK, June 2014.

[16] A. Clifton, 135m Meteorological Towers at the National Wind Technology Center, NWTC, Niagara, Wisconsin, 2016.

[17] S. Miao and S. Bo, "Influence of non-Gaussian characteristics of wind load on fatigue damage of wind turbine," Journal of Harbin Institute of Technology, vol. 49, no. 12, pp. 152-158, 2017.

[18] J. Ding and X. Chen, "Fatigue damage evaluation of broadband Gaussian and non-Gaussian wind load effects by a spectral method," Probabilistic Engineering Mechanics, vol. 41, pp. 139-154, 2015.

[19] J. J. Jensen, "Fatigue damage due to non-Gaussian responses," Journal of Engineering Mechanics, vol. 116, no. 1, pp. 240-246, 1990.

[20] H. B. Kanegaonkar and A. Haldar, "Non-Gaussian response of offshore platforms: fatigue," Journal of Structural Engineering, vol. 113, no. 9, pp. 1899-1908, 1987.

[21] J. Ding and C. Xinzhong, "Moment-based translation model for hardening non-Gaussian response processes," Journal of Engineering Mechanics, vol. 142, no. 2, Article ID 06015006, 2016.
[22] J. Ding, X. Chen, D. Zuo, and J. Hua, "Fatigue life assessment of traffic-signal support structures from an analytical approach and long-term vibration monitoring data," Journal of Structural Engineering, vol. 142, no. 6, Article ID 04016017, 2016.

[23] S. Bisoi and S. Haldar, "Dynamic analysis of offshore wind turbine in clay considering soil-monopile-tower interaction," Soil Dynamics and Earthquake Engineering, vol. 63, pp. 19-35, 2014.

[24] J. Jonkman, S. Butterfield, W. Musial, and G. Scott, Definition of a 5-MW Reference Wind Turbine for Offshore System Development, National Renewable Energy Laboratory, 1617 Cole Boulevard, Golden, Colorado, 2009.

[25] R. Damiani, J. Jonkman, A. Robertson, and H. Song, "Assessing the importance of nonlinearities in the development of a substructure model for the wind Turbine CAE tool FAST," in Proceedings of the 32nd International Conference On Ocean, Offshore And Arctic Engineering, Nantes, France, November 2014.

[26] H. Ma, J. Yang, and L. Chen, "Numerical analysis of the longterm performance of offshore wind turbines supported by monopiles," Ocean Engineering, vol. 136, pp. 94-105, 2017.

[27] G. Lloyd, Rules and Guidelines, IV Industrial Services: Guideline for the Certification of Offshore Wind Turbines, GL Renewables Certification, Hamburg, Germany, 2012.

[28] D. Kallehave, B. W. Byrne, C. LeBlanc Thilsted, and K. K. Mikkelsen, "Optimization of monopiles for offshore wind turbines," Philosophical Transactions of the Royal Society A, vol. 373, Article ID 20140100, 2015.

[29] B. J. Jonkman, TurbSim User's Guide v2.00.00 Draft Version, National Renewable Energy Laboratory, Golden, CO, USA, 2016.

[30] International Electrotechnical Commission, Wind Energy Generation Systems-Part 1: Design Requirement, International Electrotechnical Commission, Geneva, Switzerland, 2019.

[31] M. K. Ochi, "Non-Gaussian random processes in ocean engineering," Probabilistic Engineering Mechanics, vol. 1, no. 1, pp. 28-39, 1986.

[32] S. R. Winterstein and T. Kashef, "Moment-based load and response models with wind engineering applications," Journal of Solar Energy Engineering, vol. 122, no. 3, pp. 122-128, 2000.

[33] S. R. Winterstein, "Nonlinear vibration models for extremes and fatigue," Journal of Engineering Mechanics, vol. 114, no. 10 , pp. $1772-1790,1988$.

[34] S. R. Winterstein, "Moment-based Hermite models of random vibration,” Technical Report R-219, Technical University of Denmark, Lyngby, Denmark, 1987.

[35] OpenFAST documentation, 2021, https://openfast.readthedocs. io/en/main/.

[36] B. Jonkman and J. Jonkman, FAST v8.16.00a-Bjj, National Renewable Energy Laboratory, Golden, CO, USA, 2016.

[37] S. Kruch, N. Carrere, and J. Chaboche, "Fatigue damage analysis of unidirectional metal matrix composites," International Journal of Fatigue, vol. 28, no. 10, pp. 1420-1425, 2006.

[38] M.-H. H. Shen and S. Akanda, "An energy-based framework to determine the fatigue strength and fatigue ductility parameters for LCF/HCF life assessment of turbine materials," in Proceedings Of the ASME Turbo Expo 2014: Turbine Technical Conference and Exposition, Düsseldorf, Germany, June 2014.

[39] R. I. Stephens, "Fatigue design criteria," Encyclopedia Of Materials: Science and Technology, PergamonPress, pp. 2910-2918, Oxford, UK, 2nd edition, 2001. 
[40] H. Liu, H. Wang, Z. Huang, Q. Wang, and Q. Chen, "Comparative study of very high cycle tensile and torsional fatigue in TC17 titanium alloy," International Journal of Fatigue, vol. 139, Article ID 105720, 2020.

[41] S. Downing and D. Socie, "Simple rainflow counting algorithms," International Journal of Fatigue, vol. 4, no. 1, pp. 31-40, 1982.

[42] B. Yeter, Y. Garbatov, and C. Guedes Soares, "Fatigue damage assessment of fixed offshore wind turbine tripod support structures," Engineering Structures, vol. 101, pp. 518-528, 2015.

[43] Q. H. Pham, M. Gagnon, J. Antoni, A. Tahan, and C. Monette, "Rainflow-counting matrix interpolation over different operating conditions for hydroelectric turbine fatigue assessment," Renewable Energy, vol. 172, pp. 465-476, 2021.

[44] C. Han, Y. Ma, X. Qu, P. Qin, and B. Qiu, "A fast and practical method for predicting the fatigue life of offshore wind turbine jacket support structures," in Proceedings of the ASME 2017 36th International Conference On Ocean, Offshore And Arctic Engineering, Trondheim, Norway, June 2017.

[45] A. Wöhler, "Versuche über die festigkeit der eisenbahnwagenachsen," Zeitschrift für Bauwesen, vol. 10, pp. 160-161, 1860.

[46] Det Norske Veritas, Fatigue Design of Offshore Steel Structures, DNV, Bærum, Norway, 2014.

[47] E. Suhir, R. Ghaffarian, and S. Yi, "Probabilistic PalmgrenMiner rule, with application to solder materials experiencing elastic deformations," Journal of Materials Science: Materials in Electronics, vol. 28, no. 3, pp. 2680-2685, 2017.

[48] M. Ciavarella, P. D'antuono, and A. Papangelo, “On the connection between Palmgren-Miner rule and crack propagation laws," Fatigue and Fracture of Engineering Materials and Structures, vol. 41, no. 7, pp. 1469-1475, 2018. 